burgeoning population of the world. Therefore, innovative efforts to discover, develop, and formulate conventional or novel molecules to yield ecologically benign products need to be vigorously pursued and promoted to meet the needs of the future.

2. Introduction of New Technology: Approaches such as biotechnology, nanotechnology, and the like need to be carefully introduced for agricultural applications after careful evaluation of the benefits and risks, and identification of stewardship practices to accompany practical implementation.

3. Biopesticides: The simple assumption that biopesticides must be inherently safe for humans and the environment due to their natural origin is not correct. As for any crop protection product, biopesticides should be subject to evaluation and scrutiny for safety based on applicable data requirements.

4. Harmonization: International standards and guidelines for pesticide quality, safety, and environmental testing, and limits for residues in food are being developed under the auspices of such advisory bodies as FAO, WHO, CODEX, and OECD. Based on the increasing globalization of trade for both agrochemicals and food, it is recommended that national authorities and industry cooperate to the greatest extent possible in supporting and adopting such harmonized approaches. International advisory bodies should in turn monitor closely the emergence of new technologies and commodities and develop appropriate standards in a timely fashion to meet changing needs.

5. Sustainability: Sustainable agriculture requires the adoption of good agriculture practice, product stewardship, and integrated pest management on a widespread scale. Theory and methods are in place and pilot projects have demonstrated the feasibility of such approaches. It is recommended that governments, academia, and industry develop intense co-operation so as to implement these practices on a much broader basis and with a high sense of priority.

N.A. Shakil <iamshakil@gmail.com> and Jitendra Kumar are senior scientists in the Division of Agricultural Chemicals, Indian Agricultural Research Institute, New Delhi, India; they were conveners of the conference.

\section{Improving Chemical Education in the Philippines}

\author{
by Fortunato B. Sevilla III
}

A two-day conference on Improving Chemical Education in the Philippines was held at the University of Santo Tomas in Manila, Philippines, from 17-18 April 2008. The conference was a project of the IUPAC Flying Chemists Program and was organized by the Commission on Higher Education (CHED), the government body covering higher education institutions in the Philippines, in cooperation with the Kapisanang Kimika ng Pilipinas (Chemical Society of the Philippines) and the University of Santo Tomas.

This conference is a follow-up activity to the revision carried out by the CHED Technical Committee for Chemistry of the curriculum for the B.S. program for chemistry. It aimed to upgrade the course delivery methods employed by chemistry teachers in the Philippines. The project was inspired by the write-ups featured in Chemistry International on the Indian and Sri Lanka projects of the Flying Chemists Program <www.iupac.org/standing/cce/FCP.html>.

Participation in the conference, a total of 324 tertiary-level chemistry teachers, was beyond expectations. Attendees came from all the regions of the country and represented 89 different institutions of higher education in the Philippines. Among the partici-

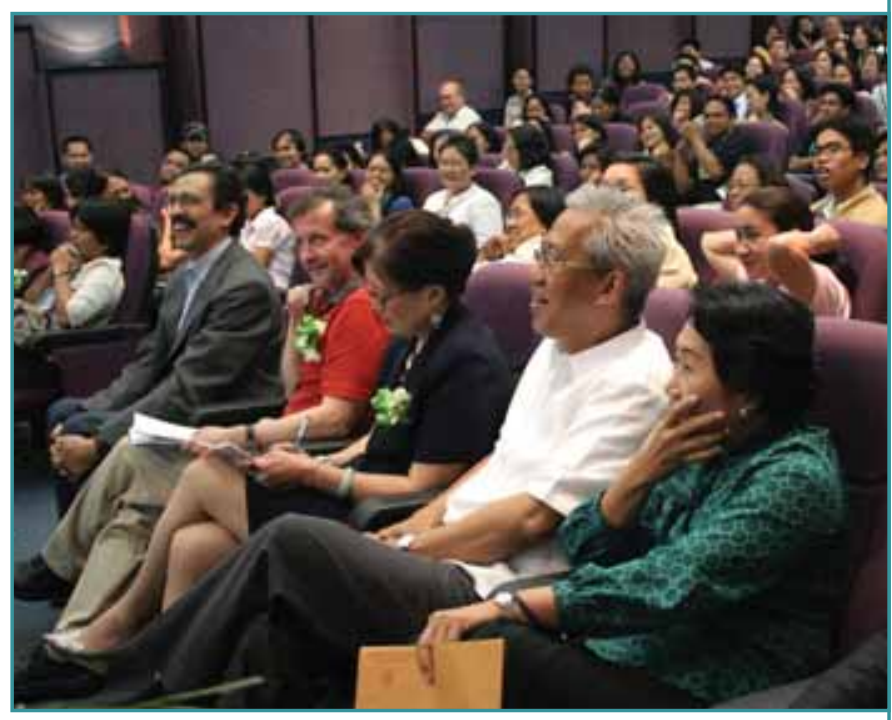

Peter Mahaffy (red shirt), chair of the IUPAC Committee on Chemistry Education, and others listen to a lecture. 
pants were 12 young chemistry teachers who received travel grants through the IUPAC Program on Financial Support of Conferences.

Five lectures were presented during the conference by IUPAC affiliated experts:

- "The Role of Visualization" by Peter Atkins of Oxford University, UK

- "New Technologies and New Tools for Chemistry Education" by Peter Mahaffy of King's University College, Canada

- "Microscale Chemistry" by Jorge G. Ibañez of the Universidad Ibero-Americana, Mexico

- "Evaluation of an Integrated Chemistry Laboratory Program at the Undergraduate Level in Taiwan" by Mei-Hung Chiu of the National Taiwan Normal University, Taiwan

- "Low-Cost Instrumentation for Chemical Education" by Fortunato Sevilla III of the University of Santo Tomas, Philippines

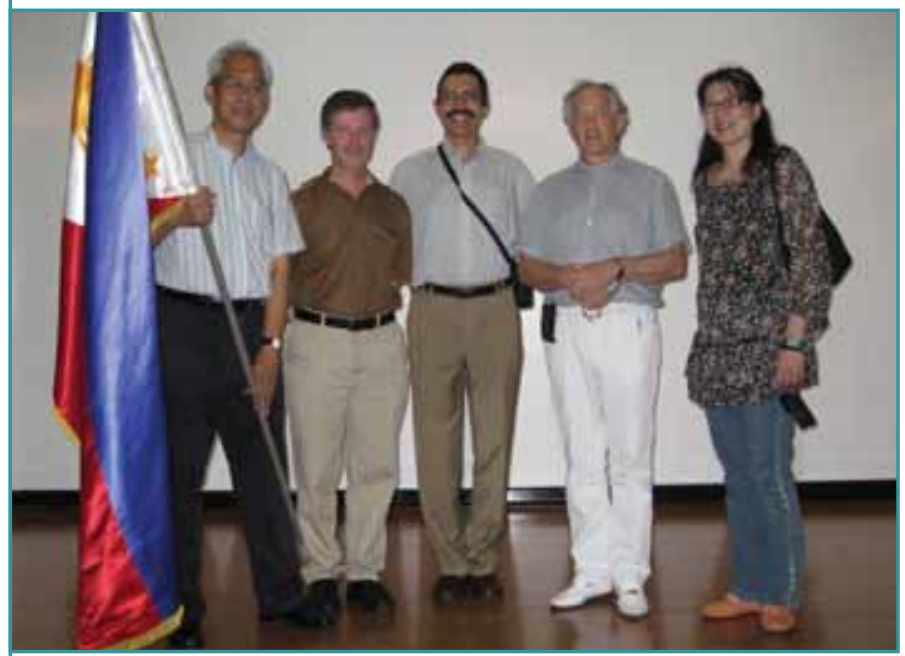

The five IUPAC lecturers, from left : Fortunato Sevilla, Peter Mahaffy, Jorge Ibañez, Peter Atkins, and Mei-Hung Chiu.

Peter Atkins demonstrated how pictures can help with simple introductory chemistry issues, such as stoichiometry and electrochemistry. Peter Mahaffy presented approaches that he has found valuable in introductory university chemistry, and gave examples of new tools for helping students to visualize the molecular world. Jorge Ibanez proved that the majority of the laboratory experiences in chemistry can be substituted using small-scale techniques without decreasing the educational gain. Fortunato Sevilla III discussed instrumentation that can be fabricated at low cost and that can be used for microscale experiments. Mei-Hung
Chiu reported on the impact of a integrated laboratory program for students at the National Taiwan University. The program uses a scaffolding structure to integrate different skills for conducting chemistry experiments needed for developing chemistry literacy.

Three workshops were conducted concurrently in two sessions of the conference. The topics of the workshops were "Visualizing Chemistry," "Low-Cost Instrumentation," and "Microscale Chemistry," which were facilitated by Peter Mahaffy, Fortunato Sevilla, and Jorge Ibañez, respectively. These workshops provided the participants with a hands-on and up-close experience with the teaching and learning resources described in the lectures. An industry-academe forum was also held, involving three presentors.

The conference opened with welcoming remarks from Fortunato Sevilla III, chair of the CHED Technical Committee for Chemistry and dean of the UST College of Science; Saturnino Ocampo Jr., CHED commissioner; and Peter Mahaffy, chair of the IUPAC Committee for Chemistry Education.

The culmination of the conference was the presentation of the output of the parallel group discussions, wherein the participants evaluated the applicability of the approaches or strategies presented in the five lectures. The participants affirmed that visualization, microscale laboratory experiments, low-cost instrumentation, and integrated laboratory courses can be implemented in various courses in the B.S. chemistry program offered by colleges and universities in the country. They expressed enthusiasm in carrying out the newly learned approaches and adopting newly learned technologies to improve the teaching and the learning of chemistry.

The output of these discussions provided the basis for the actions that will be taken to improve chemistry education. The outcome of these actions will be reported during the 2009 Philippine Chemistry Congress, wherein several sessions will focus on chemistry education. The participants agreed to present papers during the congress on their endeavors to apply the tools and strategies expounded by the IUPAC speakers. Indeed, the IUPAC "flying chemists" have become partners of the Philippine chemistry teachers in their goal to upgrade chemical education in the Philippines.

Fortunato Sevilla <fbsevilla@mnl.ust.edu.ph> is a professor at the University of Santo Tomas, Department of Chemistry, Manila, Philippines. He chaired this activity under the IUPAC Flying Chemist Program, IUPAC project 2007-018-1-050. 